\title{
Mid-Infrared GaAs/AlGaAs Quantum Cascade Lasers Technology
}

\author{
A. Szerling, P. Karbownik, K. Kosiel, J. Kubacka-TraczyK, \\ E. Pruszyńska-Karbownik, M. PŁuska and M. Bugajski \\ Institute of Electron Technology, al. Lotników 32/46, 02-668, Warsaw, Poland
}

\begin{abstract}
The fabrication technology of AlGaAs/GaAs based quantum cascade lasers is reported. The devices operated in pulsed mode at up to $260 \mathrm{~K}$. The peak powers recorded at $77 \mathrm{~K}$ were over $1 \mathrm{~W}$ for the $\mathrm{GaAs}_{2} / \mathrm{Al}_{0.45} \mathrm{Ga}_{0.55} \mathrm{As}$ laser without anti-reflection/high-reflection coatings.
\end{abstract}

PACS numbers: 42.55.Px, 85.60.-q, 85.35.Be, 72.80.Ey, 73.61.Ey, 78.66.Fd

\section{Introduction}

The quantum cascade lasers (QCLs) are unipolar devices based on intersubband transitions and tunnelling transport $[1,2]$. The GaAs-based QCLs have proved to be an effective source of laser radiation in mid-infrared (MIR) as well as far-infrared (FIR) regions. They find application in the gas sensing systems (e.g., for detecting $\left.\mathrm{CO}_{2}, \mathrm{NO}, \mathrm{CH}_{4}\right)$ [3], medical diagnostics [4] and environment monitoring [5].

The complex design and operating principle require the technology of quantum cascade lasers to ensure the highest accuracy, uniformity and repeatability of both epitaxy and device processing [6]. High requirements for epitaxy are connected with ultrathin layers of periodic active region, where the wave functions are to be properly engineered [7-9]. The thickness accuracy of the structure should in general be better than $3 \%$. Another crucial issue is the optimisation of injector doping, which is necessary to assure a large enough dynamic range of laser operation $[10,11]$. In order to restrict the lateral current spreading in the device it is necessary to form a good quality deep mesa structures. Since the available gain is usually limited, the device design should minimize the radiation losses. The mesa is etched through active region and reduction of the optical losses requires a smooth waveguide sidewalls [12]. There is a number of QCLs designs reported in the literature $[6,13]$. Sirtori et al. [6]. have presented the ridge structure and double trench structure, in which ion implantation was used for electrical isolation instead of dielectric layers. The optimum one seems to be the double trench construction which insures a good overlapping of the lateral mode with the gain region and enables stable epi-down mounting necessary for efficient cooling of the device [14]. The construction in which the extended proton-implanted regions were applied in the area defined by the two trenches, was the another presented solution. In this case the channel for current injection was narrower than the ridge width, which minimizes absorption of generated radiation in dielectric layers insulating mesa sidewalls $[6,15]$.

As a rule the relatively high voltages as well as current densities are necessary to polarize QCLs. That indicates demand for low resistance ohmic contacts in order to reduce the device serial resistance. These contacts should be characterized by thermal stability, low depth of metal diffusion into semiconductor layers and lateral uniformity of metal-semiconductor interfaces.

In this paper we discuss some issues fabrication technology of $\mathrm{Al}_{0.45} \mathrm{Ga}_{0.55} \mathrm{As} / \mathrm{GaAs} \mathrm{QCL}$ operating at $\lambda \approx$ $9.4 \mu \mathrm{m}$. The devices lased up to $262 \mathrm{~K}\left(-11^{\circ} \mathrm{C}\right)$ with optical powers over $1 \mathrm{~W}$ at $77 \mathrm{~K}$, threshold current density values of $7 \mathrm{kA} \mathrm{cm}^{-2}$ and differential efficiencies above $0.6 \mathrm{~W} / \mathrm{A}$. Since lasers were uncoated, the quoted values should be understood.

\section{Molecular beam epitaxy of quantum cascade lasers}

The layer sequence in the QCL heterostructure is presented in Fig. 1. The structure contained 36 period cascade and followed the scheme originally proposed by Page et al. [2].

Two barrier-quantum well (QW) pairs in the central part of each injector have been doped. The structure used double-plasmon Al-free waveguide for planar optical confinement. Detailed description of the MBE growth procedures can be found in Refs. $[8,9]$.

As it has been mentioned earlier, the principle of operation of quantum cascade lasers requires strictly determined individual layer thickness and composition as well as the overall periodicity of the whole structure. The laser operation is possible only when the designed structure is realized, with the extreme technological precision concerning geometrical and doping features. 


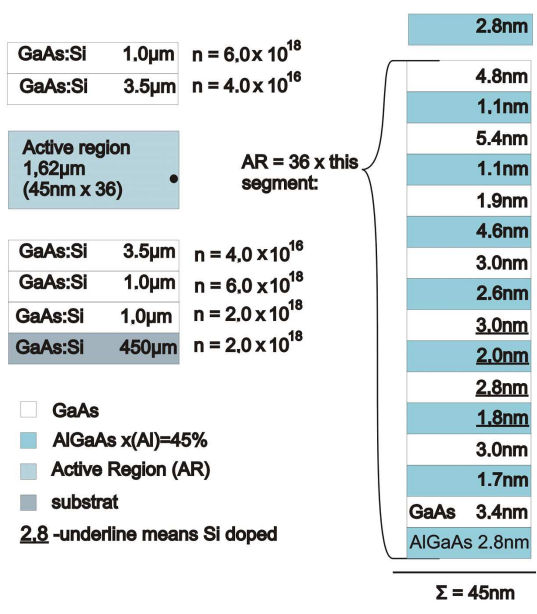

Fig. 1. The schematic sequence of layers in QCL structure.

To obtain information about the thickness and composition of constituent layers in QCL structures, a theoretical analysis of $2 \Theta /$ omega scans was carried out. The comparison between the measured curves and the simulated ones for the planned structure was made. Analysis of high resolution X-ray diffraction (HRXRD) (see Fig. 2a) shows almost perfect agreement between optimized laser structure and simulated one referring to the intended design. This is seen from matching the measured and calculated satellite peak positions. Better than $1 \%$ thickness accuracy has been routinely achieved. Figure $2 \mathrm{~b}$ presents the X-ray reciprocal space map clearly showing absence of any extended defects in the studied structure.
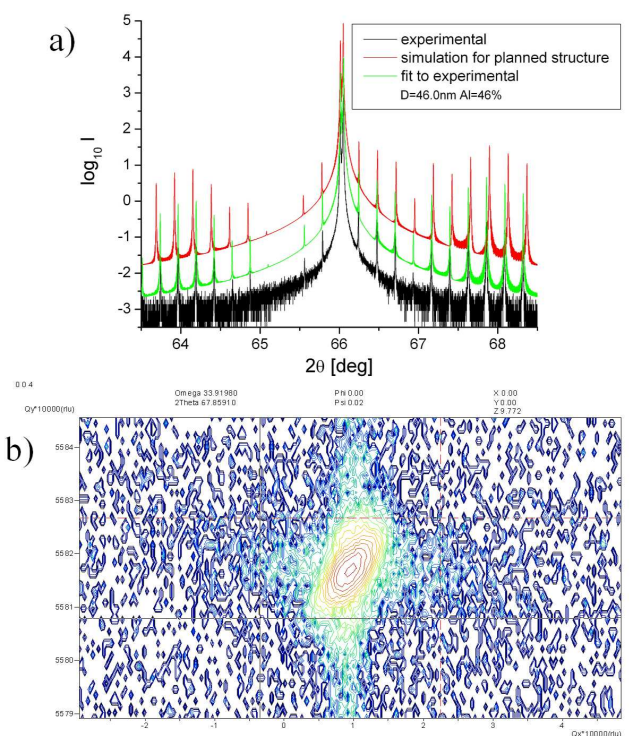

Fig. 2. The comparison of the HRXRD rocking curves for QCL $45 \%$ : measured, fitted and simulated for the intended construction (a) and X-ray reciprocal space map (b).

\section{Processing of quantum cascade lasers}

One of the main problems concerning the QCL devices is high operating current generating strong self-heating effect. This current may be decreased by reduction of the pumped area and by appropriate device processing. The double-trench construction was adapted in order to limit the lateral current spreading in the device. In Fig. 3 we present quantum cascade laser mounted epi-down with $\mathrm{Au} / \mathrm{Sn}$ eutectic on diamond heatspreader and copper submount.

a)
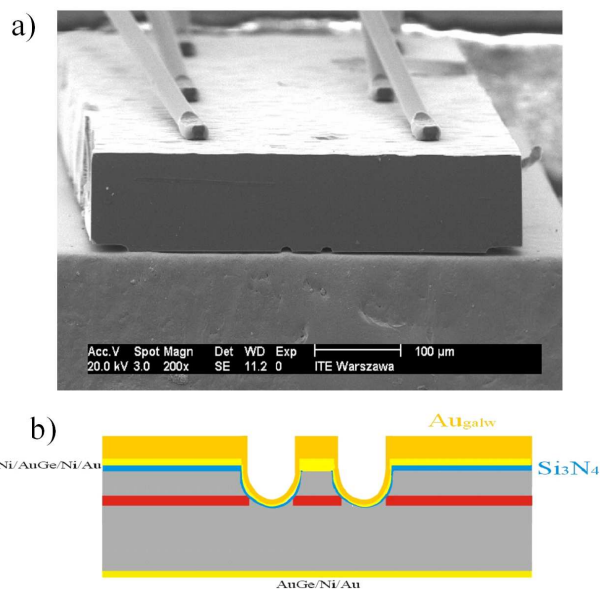

Fig. 3. $\mathrm{Al}_{0.45} \mathrm{Ga}_{0.55} \mathrm{As} / \mathrm{GaAs}$ quantum cascade laser made in IET (a) and cross-section of the device (b).

The lasers were fabricated by standard processing technology, i.e. photolithography and wet etching $\left(\mathrm{HCl}: \mathrm{H}_{2} \mathrm{O}_{2}: \mathrm{H}_{2} \mathrm{O}=40: 4: 1\right)$ for the depth slightly beyond the active region $(\mathrm{AR})$ - Fig. 4. A particular attention was paid to obtaining the good quality of mesa side walls necessary to minimize scattering losses.

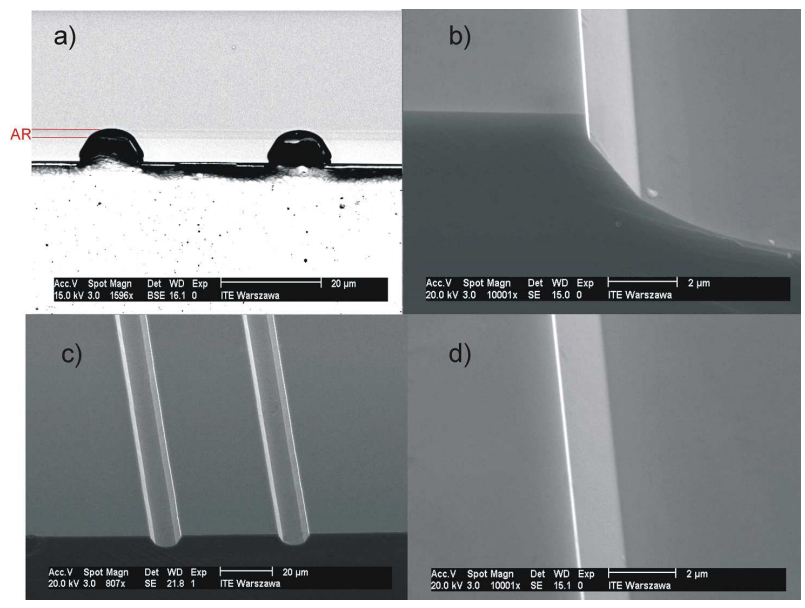

Fig. 4. Scanning electron micrographs of the double-trench laser structures formed by wet etching; the etching process stops just beyond the AR (a); excellent quality of mesa side walls (b)-(d). 
In contrast to the approach adopted by Sirtori et al. [6] and Page et al. [13]. we have used $\mathrm{Si}_{3} \mathrm{~N}_{4}$ for electrical insulation (Fig. 5). A $300 \mathrm{~nm} \mathrm{Si}_{3} \mathrm{~N}_{4}$ layer was grown by plasma enhanced chemical vapor deposition (PECVD). This material is much better than $\mathrm{SiO}_{2}$ film, because it shows smaller absorption at the wavelength of emission of our lasers $(\lambda \approx 9 \mu \mathrm{m})$.

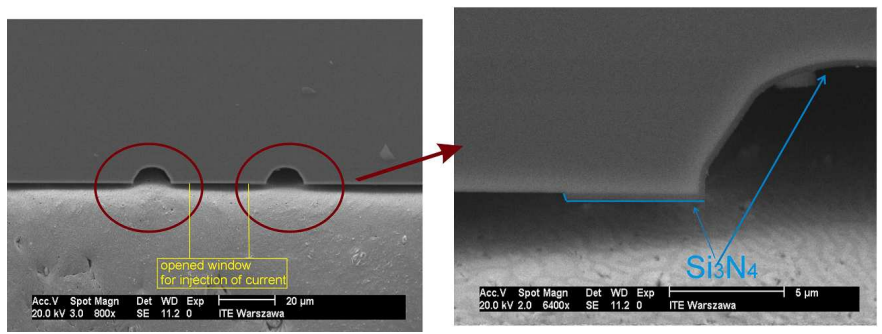

Fig. 5. Scanning electron micrograph of the double-trench lasers with dielectric isolation.

The $\mathrm{Si}_{3} \mathrm{~N}_{4}$ insulating film has been placed on the surface of both trenches and elongated in the form of two $5 \mu \mathrm{m}$ wide stripes on the top of the ridge (see Fig. 5). On the basis of the scanning electron microscopy (SEM) micrographs it is believed that $\mathrm{Si}_{3} \mathrm{~N}_{4}$ layer is of high quality and uniformity, and it forms a very good electrical isolation. For current injection, the windows were opened in the insulator with width of 25,35 , and $50 \mu \mathrm{m}$.

To minimize series resistance of the device a good quality ohmic contacts have to be formed. We have investigated $5 \mathrm{nmNi} / 100 \mathrm{nmAuGe} / 35 \mathrm{nmNi} / 300 \mathrm{nmAu}$ metallization system for our structures. Commonly, the $\mathrm{AuGe} / \mathrm{Ni} / \mathrm{Au}$ metallic system is used for ohmic contacts for $n$-type GaAs $[16,17]$. However adding the layer of $\mathrm{Ni}$ between GaAs and AuGe improves metal adhesion [18] and results in formation of diffusion barrier for Ge and $\mathrm{Au}[19]$. This allows for application of such system as $n$-type ohmic contact to the epitaxial layer. The achieved average specific contact resistance was about $6 \times 10^{-7} \Omega \mathrm{cm}^{-2}$. Details on the optimization of the ohmic contact can be found in Ref. [20]. After formation of the contact to epi-side, the wafer was thinned down to about $100 \mu \mathrm{m}$, and alloyed $\mathrm{AuGe} / \mathrm{Ni} / \mathrm{Au}$ contact was deposited on the backside. The lasers were cleaved into bars of 1 and $2 \mathrm{~mm}$ length and soldered with $\mathrm{Au} / \mathrm{Sn}$ eutectic, epilayer down on diamond heatspreader and copper submounts.

\section{Parameters of devices}

Figure 6 shows $V-I$ and $P-I$ characteristics for two lasers at $77 \mathrm{~K}$ and for one laser at $300 \mathrm{~K}$. For low bias regime the lasers $(77 \mathrm{~K})$ are highly resistive, after voltage drop $\approx 6 \mathrm{~V}$ electrons start to flow through the device. In this region the operating voltage increases linearly with injection current. The saturation of the $V-I$ characteristics, observed at about $11 \mathrm{~V}$ (Fig. 6a), is caused by the onset of misalignment between the upper laser level and the injector ground state. This effect depends on the injector doping density and limits the dynamic range of laser operation $[10,11]$. For the structures with higher injector doping the effect of current saturation is not clearly observed (Fig. 6b).

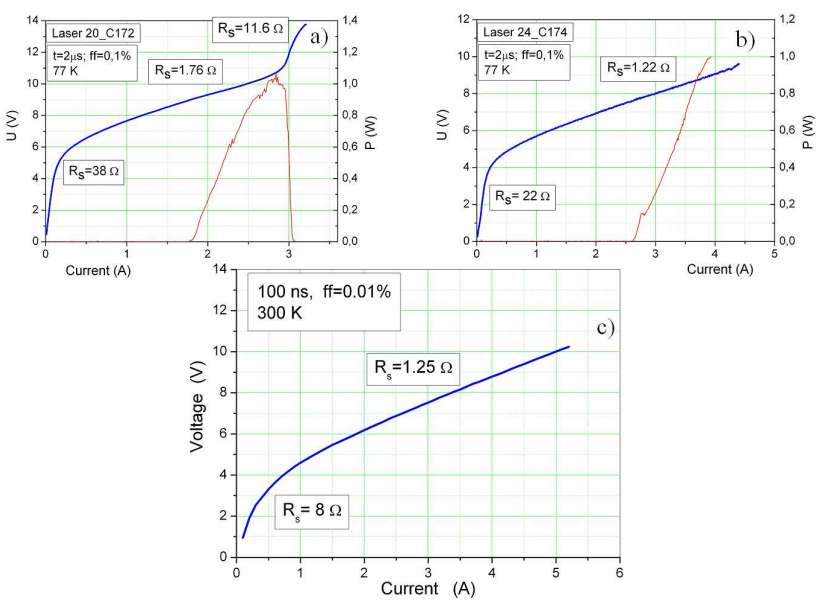

Fig. 6. The $V-I$ and $P-I$ characteristics of the lasers fabricated from $\mathrm{GaAs} / \mathrm{Al}_{0.45} \mathrm{Ga}_{0.55} \mathrm{As}$.

At higher temperature $(300 \mathrm{~K})$ the biased lasers are less resistive $(R=8 \Omega)$ than the same devices measured in $77 \mathrm{~K}$ (Fig. 6c). We believe that this phenomenon is connected with carriers leakage into continuum states at higher temperatures. At higher polarization, when the levels start to be properly aligned, the laser resistance drops to the value similar to the one observed at low temperatures $(77 \mathrm{~K})$.

The $77 \mathrm{~K}$ light-current and current-voltage characteristics for the GaAs $/ \mathrm{Al}_{0.45} \mathrm{Ga}_{0.55}$ As laser without antireflection (AR)/high-reflection (HR) coatings are presented in Fig. 7 . The laser was driven by $2 \mu$ s pulses with repetition rate of $0.5 \mathrm{kHz}$. The laser emission was recorded with TE cooled $\mathrm{HgCdTe}$ detector. The detector active area was $0.3 \times 0.3 \mathrm{~mm}^{2}$. Light from the laser was shined directly on the detector, without collimating lens. The quantum cascade lasers presented in this paper are multimode devices. This is the reason of the two peak behavior of the structure with $W=25 \mu \mathrm{m}$, presented in Fig. 7b.

For the $1 \mathrm{~mm} \times 25 \mu \mathrm{m}$ device operated in pulse mode, we have obtained optical powers between 10 and $40 \mathrm{~mW}$ for the temperatures $230-240 \mathrm{~K}$. This temperature range is accessible on the TE coolers, which makes the device suitable for field applications. The record $(2 \mathrm{~mm} \times 25 \mu \mathrm{m})$ device lased up to $262 \mathrm{~K}\left(-11^{\circ} \mathrm{C}\right)$.

\section{Conclusions}

The fabrication technology of $\mathrm{AlGaAs} / \mathrm{GaAs}$ based QCLs emitting at $9 \mu \mathrm{m}$ was presented. The devices operated in pulsed mode at up to $260 \mathrm{~K}$. The peak powers recorded at $77 \mathrm{~K}$ were over $1 \mathrm{~W}$, and the slope efficiency 


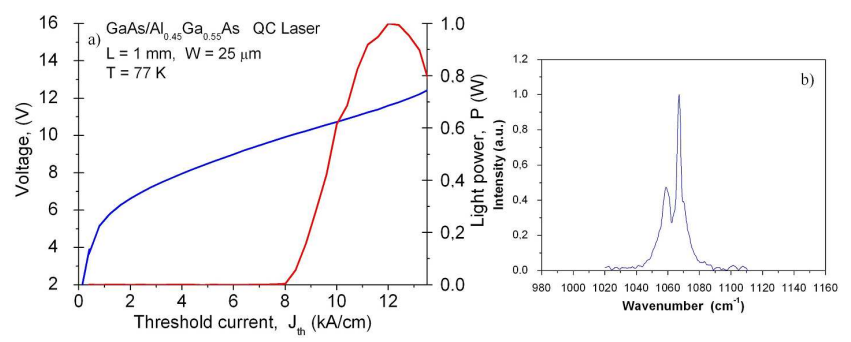

Fig. 7. Light output and current-voltage characteristics (a) and the spectral characteristic (b) of the device operated at $77 \mathrm{~K}$ in pulsed mode with powers up to $1 \mathrm{~W}$ per uncoated facet.



Fig. 8. The laser power as a function of temperature.

$\eta \approx 0.5-0.6 \mathrm{~W} / \mathrm{A}$ per uncoated facet. These results are fully comparable wit the state of the art devices of similar design produced in other laboratories.

\section{Acknowledgments}

Authors would like to thank Dr. Ewa Papis, Anna Barańska and Krzysztof Hejduk for helpful discussions and help in technological processes, Dr. Kamil Pierściński, Dr. Dorota Pierścińska for spectral measurements and Leszek Ornoch for assistance in electrical characterization. The work was financially supported by grant PBZ-MIN-02/I/2007.

\section{References}

[1] J. Faist, F. Capasso, D.L. Sivco, C. Sirtori, A.L. Hutchinson, A.Y. Cho, Science 264, 553 (1994).

[2] H. Page, C. Becker, A. Robertson, G. Glastre, V. Ortiz, C. Sirtori, Appl. Phys. Lett. 78, 3529 (2001).
[3] A. Kosterev, G. Wysocki, Y. Bakhirkin, S. So, R. Lewicki, M. Fraser, F. Tittel, R.F. Curl, Appl. Phys. B 90, 165 (2008).

[4] B.W.M. Moeskops, H. Naus, S.M. Cristescu, F.J.M. Harren, Appl. Phys. B 82, 649 (2006).

[5] M.I. Tihov, M.Sc. Thesis, 2003.

[6] C. Sirtori, H. Page, C. Becker, V. Ortiz, IEEE J. Quantum Electron. 38, 547 (2002).

[7] C. Sirtori, GaAs Quantum Cascade Lasers: Fundamentals and Performance, EDP Sciences, Orsay 2002.

[8] K. Kosiel, J. Kubacka-Traczyk, P. Karbownik, A. Szerling, J. Muszalski, M. Bugajski, P. Romanowski, J. Gaca, M. Wójcik, Microelectron. J 40, 565 (2009).

[9] K. Kosiel, M. Bugajski, A. Szerling, J. Kubacka-Traczyk, P. Karbownik, E. Pruszyńska-Karbownik, J. Muszalski, A. Łaszcz, P. Romanowski, M. Wasiak, W. Nakwaski, I. Makarowa, P. Perlin, Photonics Lett. Poland 1, 16 (2009).

[10] S. Höfling, R. Kallweit, J. Seufert, J. Koeth, J.P. Reithmaier, A. Forchel, J. Cryst. Growth 278, 775 (2005).

[11] S. Höfling, V.D. Jovanović, D. Indjin, J.P. Reithmaier, A. Forchel, Z. Ikonić, N. Vukmirović, P. Harrison, A. Mirćetić, V. Milanović, Appl. Phys. Lett. 88, 251109 (2006).

[12] F. Toor, D.L. Sivco, H.E. Liu, C.F. Gmachl, Appl. Phys. Lett. 93, 031104 (2008).

[13] H. Page, S. Dhillon, M. Calligaro, V. Ortiz, C. Sirtori, Electron. Lett. 39, 1053 (2003).

[14] H. Page, A. Robertson, C. Sirtori, C. Becker, G. Glastre, J. Nagle, IEEE Photon. Technol. Lett. 13, 556 (2001).

[15] H. Page, S. Dhillon, M. Calligaro, C. Becker, V. Ortiz, C. Sirtori, IEEE J. Quantum Electron. 40, 665 (2004).

[16] Y.-C. Shin, M. Murakami, E.L. Wilkie, A.C. Callegari, J. Appl. Phys. 62, 582 (1987).

[17] J. Stock, J. Malindretos, K.M. Indlekofer, M. Pöttgens, A. Förster, H. Lüth, IEEE Trans. Electron Dev. 48, 1028 (2001).

[18] M. Murakai, Sci. Technol. Adv. Mater. 3, 1 (2002).

[19] F. Vidimari, Electron. Lett. 15, 674 (1979).

[20] P. Karbownik, A. Barańska, A. Szerling, W. Macherzyński, E. Papis, K. Kosiel, M. Bugajski, M. Tłaczała, R. Jakieła, Opt. Appl. in press. 